Mason, ${ }^{1}$ who has used the method extensively, says:

"Usually four $50 \mathrm{cc}$. tubes will be sufficient to carry off all the free ammonia, but it is the author's custom always to distil off six."

Stocks ${ }^{2}$ says:

"In distilling ordinary waters, practically the whole of the ammonia will be present in the first Ioo cc., but with sewages the whole of the ammonia may not have been obtained even after distilling $300 \mathrm{cc}$, and it is, therefore, necessary in such cases to allow the retort to cool, make up to the original volume with distilled water and continue the distillation. The albuminoid ammonia being formed by the oxidation of organic matter, is not evolved so quickly as the free ammonia, hence it may be necessary to distil several Ioo cc. portions before it ceases to be evolved."

"The "Standard Methods of Water Analysis" (I9I2 Edition) recommends the collection of three $50 \mathrm{cc}$. portions for the free ammonia, and at least four, preferably five, $50 \mathrm{cc}$. portions for albuminoid ammonia. This procedure we were using until we saw an advance copy of the Revision of the Standard Methods and learned that it was recommending a collection of four $50 \mathrm{cc}$. Nessler tubes in the distillation of the free ammonia and five in the case of albuminoid ammonia.

In order to see what influence this procedure would have upon the results obtained, we began a statistical study of the quantities of ammonia collected in each tube, as well as the total amount obtained. The results of this study are herein contained.

We have been following the revised procedure for several months, using it on all classes of water. The total number of waters examined was between 500 and I000; the free ammonia varied from 0.002 to 2.0 parts per million, and the albuminoid from 0.002 to 4. 0 parts per million. A compilation of all of the results, with regard to amount and rate of ammonia distilling, were made and the conclusions obtained were as follows

Nitrogen As FreE Ammonia

Fourth tube averages 5 per cent of the total nitrogen

76 per cent of the waters had 100 per cent nitrogen in 3 tubes

24 per cent of the waters had 95 per cent nitrogen in 3 tubes

50 per cent of the waters had 50 to 55 per cent nitrogen in 1 tube
20 per cent of the waters had 65 to 70 per cent nitrogen in 1 tube Nitrogen as AlBuminom AMmonia

Fifth tube averages 5 per cent of the total nitrogen

75 per cent of the waters had 100 per cent nitrogen in 4 tubes
25 per cent of the waters had 95 per cent nitrogen in 4 tubes

30 per cent of the waters had 50 to 60 per cent nitrogen in 1 tube
20 per cent of the waters had 60 to 70 per cent nitrogen in 1 tube

Those waters which had 5 per cent of the nitrogen in the last tube had a total nitrogen content of either free or albuminoid ammonia of $I$ part per million or more of nitrogen. Since ordinary waters, unless grossly polluted, contain less than I part per million of nitrogen as free or albuminoid ammonia, we can conclude that the collection of a $4^{\text {th }}$ tube in the free ammonia determination and $a^{\text {th }}$ in the albuminoid determination, under ordinary circumstances, is not necessary. Furthermore, the average per cent found in the last tube, including all samples, was only 5 per cent of the total nitrogen.

In a water containing less than I part per million the maximum error is 0.05 part per million; in a water containing 4 parts per million, the maximum amount found in the waters examined, the error is 0.2 part per million. In other words, in one case we would report $0.95 \mathrm{p}$. p. m. of nitrogen and in the other 3.80 .

I "Examination of Water," 1913, 62.

? "Water Analysis," 1912, 11 .
However, since the ammonia determination is not quantitative and the results are used only as a basis for determining pollution, the question to be decided is whether or not the error of $0.05 \mathrm{p} . \mathrm{p} . \mathrm{m}$. in one case and 0.2 in the other, would cause a change of judgment. We think it would not; that is, a water with I p. p. m. of nitrogen would stand as good a chance of being condemned as one containing 0.95 p. p. m., if all the other evidences pointed towards contamination.

We conclude, therefore, from this study that in order to get sufficient information upon which to base a judgment, it is not necessary, in ordinary routine water analysis, to nesslerize more than three $50 \mathrm{cc}$. portions for free ammonia, and four $50 \mathrm{cc}$. portions for albuminoid ammonia.

\footnotetext{
WATER and Sewage Laboratory
}

UNIVERSTTY OF KANSAS, LAWRENCE

\section{A MODIFICATION OF MCCRUDDEN'S METHOD FOR \\ CALCIUM, FOR THE ESTIMATION OF CALCIUM AND STRONTIUM IN THE PRESENCE OF PHOSPHORIC ACID AND A SMALL AMOUNT OF IRON}

BY 0 . B. WINTER

Received August 11, 1915

The method ${ }^{1}$ generally used in estimating calcium and strontium, when both are present in a solution, is to precipitate them as the oxalates, burn to the oxides, change to the nitrates, separate the calcium nitrate from the strontium nitrate by means of absolute alcohol and ether, and then determine each element separately. If phosphoric acid and iron are also present in the solution with the calcium and strontium salts, the separation becomes much more difficult since calcium, strontium and iron phosphates are quite insoluble in a neutral or alkaline solution. In this latter case, the phosphoric acid and iron are removed before the calcium and strontium are determined. This is usually accomplished by precipitating ${ }^{2}$ the phosphoric acid as ferric phosphate, and the excess of iron as ferric subacetate. However, when there is a large amount of phosphoric acid in the solution, this method becomes tedious because the bulky, gelatinous precipitate formed causes the solution to filter very slowly, and it is almost impossible to wash all of the calcium and strontium salts out of this precipitate.

McCrudden has worked out a method" for "The quantitative separation of calcittm and magnesium in the presence of phosphoric acid and small amounts of iron, devised especially for the analysis of foods, urine and feces." By this method the calcium is precipitated very slowly as the oxalate in a boiling solution containing a small amount of free hydrochloric acid. This gives rise to a condition in which the calcium oxalate comes down very coarsely crystalline, and apparently no soluble salts are carried down by occlusion.

The above method was found accurate for the estimation of calcium, but in trying it out on a strontium

1 U. S. Dept. of Agr., Bureau of Chemistry, Bull. 162, 44.

"Perkin, "Methods in Qual, Analysis." p. 76

J. Biol. Chem. 7 (1909), 83. 
solution, it was found that this element ran low, but not so much so as was anticipated. Several different modifications of the method were attempted and finally it was shown that the addition of alcohol would insure complete precipitation of strontium. The following method gave very satisfactory results for both calcium and strontium:

Dilute the solution containing the calcium or strontium, or both, to about $200 \mathrm{cc}$. and add a few drops of alizarine and ammonium hydroxide until the solution is faintly alkaline. Now add dilute hydrochloric acid until the solution is faintly acid. To this solution add ro cc. of $0.5 \mathrm{~N}$ hydrochloric acid and ro cc. of 2.5 per cent of oxalic acid, and boil until the precipitate becomes coarsely granular. Then add saturated ammonium oxalate solution, a few drops at a time with constant stirring, until about twice the amount necessary to precipitate all the calcium and strontium has been added. Cool the solution, add, with constant stirring, $8 \mathrm{cc}$. of 20 per cent sodium acetate solution and about $\mathrm{I} 5 \mathrm{cc}$. of 95 per cent alcohol, and allow to stand from 4 to 8 hours. Filter and wash the precipitate a few times with $\mathrm{I}$ per cent ammonium oxalate solution, several times with I per cent ammonium oxalate solution containing 20 per cent by volume of alcohol, and finally a few times with water containing 20 per cent by volume of alcohol. Now burn the precipitate to the oxide, dissolve in nitric acid, dehydrate, separate the calcium nitrate from the strontium nitrate by means of absolute alcohol and ether, and determine each element in the usual manner.

That this modified method gives quantitative results is shown in the accompanying table, which gives the analyses of synthetic solutions of calcium and strontium salts. The amount of calcium in these solutions was determined by precipitating it as the oxalate $^{2}$ in a neutral solution and then burning to the oxide, after first removing the phosphoric acid with ferric chloride ${ }^{3}$ and the excess of iron as ferric subacetate. The strontium in the solutions was estimated as the sulfate $e^{4}$ and calculated to the oxide.

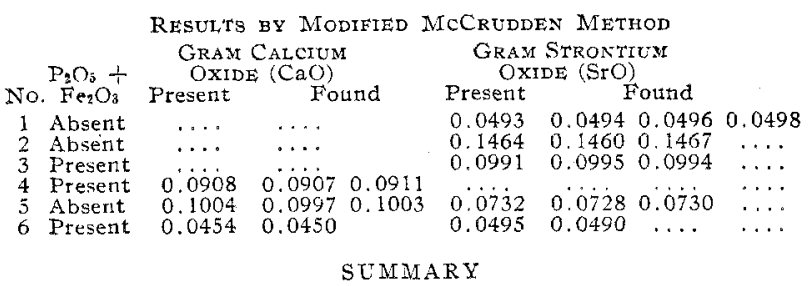

I-McCrudden's method with the modifications given in this paper may be used for determining calcium or strontium.

II-This modified McCrudden method is accurate and convenient for determining calcium and strontium when both are present in a solution containing phosphoric acid and a small amount of iron.

Michigan Agricultural College Experiment Station East Lansing, Michigan

1 U. S. Dept. of Agr., Bureau of Chemistry, Bull, 162, 44.

"Treadwell-Hall, "Analytical Chem.": "Quant. Analyses," 1st Ed., $2(1909), 65$.

"Perkin "Methods in Qual. Analysis," p. 76

'Treadwell-Hall, "Analytical Chem.": "Quant. Analyses," 1st. Ed., 2 (1909), 66.

\section{BIOCHEMICAL CHANGES IN COTTONSEED IN STORAGE}

By J. B. RATHER

Received March 25, 1916

The investigation here reported is an outgtowth of a study of the effect of storage on the vitality of cottonseed planned and conducted by the Department of Agronomy of the Arkansas Experiment Station. The field work gave opportunity to study changes in the seed with reference to the possible deterioration from the standpoint of the feeder of live stock and the mantifacturer of cottonseed oil. With this in mind, samples of cottonseed collected in the work on the vitality of cottonseed were examined as described below.

No mention of the biochemical changes which take place in stored cottonseed has been found in the literature. It is common knowledge, however, that cottonseed will heat and deteriorate in storage under certain conditions. This heating is undesirable from the standpoint of the oil mill because it leads to the production of low-grade cottonseed oil, dark in color and high in free fatty acids. There is a larger loss in refining such oil, and as cottonseed oil is sold to the refiners on the basis of that factor, the oil mills constantly watch for heating in their storage bins, and move the heated seed out as rapidly as possible. $A$ priori, then, cottonseed that has heated would be expected to be high in free fatty acids. The work of various investigators on the deterioration of corn (maize) in storage ${ }^{2}$ indicates that cottonseed would probably increase also in total acidity under similar conditions.

\section{EXPERIMENTAI}

The field work of this investigation was conducted at Morrilton, Arkansas, during the seasons of I9I4 and I9I 5 , by Mr. M. S. Baker of the Department of Agronomy of this Experiment Station. Morrilton is in a typical cotton section of the state, and the soil selected was as nearly uniform as possible.

A five-bale lot of seed cotton, from native Mebane's Triumph seed, was harvested in mid-season, while dry, and stored the same day in an oil mill seed bin. After a storage period of $2 \mathrm{I}$ days it was ginned, and the seed $(5000 \mathrm{lbs}$.) stored in a pile I $2 \mathrm{ft}$. by I $2 \mathrm{ft}$. by $6 \mathrm{ft}$. in an oil mill seed bin for a period of 77 days. Samples were taken immediately after harvest, when the seed was ginned, and whenever the temperature of the seed seemed to warrant it. In sampling the cottonseed a sampler was used which took the sample from top to bottom of the bin at the point desired. Four thermometers were placed in different parts of the bin and accurate records kept of the changes in temperature. The samples were forwarded to the laboratory in air-tight containers, and as soon as possible after their arrival a portion of each was ground for analysis. Moisture, fat, free fatty acids in fat, crude protein, albuminoids, and total acidity determinations were

1 Full details of these and additional experiments will be published as a Bulletin of the Arkansas Experiment Station.

2 See Black and Alsberg. Bur. Plant Ind., U. S. Dept. Agr., Bull. 199; Besley and Baston, U. S. Dept. Agr., Bull. 102; and references there given. 